\title{
Action of Lead-tetra-ethyl in Delaying Detonation in the Internal Combustion Engine.
}

\section{By Dr. E. MaRdues.}

$\mathrm{T}^{\mathrm{H}}$ HE arrival in Great Britain from the United States of ethyl petrol-the anti-knock fuel containing 6 c.c. of ethyl fluid (lead-tetra-ethyl $\mathbf{5 4 . 5}$ per cent.; ethylene dibromide 36.5 per cent. ; and monochlornaphthalene 9 per cent., with a trace of Sudan IV. Red dye) per gallon of petrol, has aroused public interest in the remarkable action of minute quantities of lead-tetra-ethyl and other substances in delaying detonation or 'knocking' in the internal combustion engine. Questions have been raised in the daily press with regard to the benefits to be derived from the use of 'doped' fuel, and as to whether its use is attended with any ill effects on the health or any deleterious action on the mechanism of the engine.

In brief, distinct advantages are to be gained by the use of 'anti-knock' fuels; deleterious action on the engine mechanism by the use of ethyl petrol, if any, is negligible, whilst after investigations in the United States no grave poison hazard appears to have been discovered. The petrol has been sold in America since 1923, and although about 800 million gallons U.S. have been consumed, no illness attributable to its use has been found. In Germany iron-penta-carbonyl in petrol is marketed under the name Motalin as an anti-knock fuel.

\section{Action of Lead-TETRa-ethyL.}

The main function of the lead-tetra-ethyl is to mitigate the distressing engine trouble of 'knocking 'or detonation which arises when a car is accelerating or climbing with open throttle on top gear, especially when the cylinders contain carbon deposits or when an inferior fuel is used. The halogen compounds, namely, ethylene dibromide and monochlornaphthalene, help to remove the lead from the cylinder in the form of lead halogen compounds after the lead-tetra-ethyl has done its work, and they also contribute slightly to the anti-knock action.

It has been found impossible to use an ordinary straight run petrol for high compression engines such as are used for aeronautical or racing purposes without loss of power due to detonation, and it is necessary to employ either mixtures of petrol with benzene, alcohol, etc., for these purposes or to add a small amount of an anti-knocker, such as leadtetra-ethyl. Ethyl petrol with increased amounts of 'dope' was employed in the winning of the Schneider Trophy (1927) and by Capt. M. Campbell in establishing the world's record of motor-car speed, February 1928.

\section{Engine Experiments with Ethyl Petrol.}

For ordinary purposes the following engine experiments illustrate the typical action of 5 c.c. ethyl fluid per gallon of petrol. In a comparatively low performance water-cooled engine which detonated badly at 5 to 1 compression ratio when run on petrol alone, detonation was immediately suppressed when run on the ethyl mixture, and the compression could be raised to $6: 1$ before detonation began. It was calculated from the data obtained that an increase in power of 10.5 per cent. and a decrease in consumption of fuel of 6 per cent. were obtained by employing the higher compression.

In a high performance air-cooled engine at 5:1 compression ratio, a slight gain in power was always noticed on changing over from petrol to the ethyl mixture without altering any other condition. Detonation as before was suppressed, and a further gain in power could be got by increasing the magneto advance.

\section{Compression and EFficiency.}

The development of the internal combustion engine has been seriously impeded by the tendency of an ordinary straight run petrol to detonate when the compression ratio is raised above 5 . It will be seen from Table I., prepared from tests carried out

TABLE I.

\begin{tabular}{|c|c|c|}
\hline $\begin{array}{c}\text { Compression } \\
\text { Ratio. }\end{array}$ & $\begin{array}{c}\text { Indicated Horse- } \\
\text { power. }\end{array}$ & $\begin{array}{c}\text { Indicated Thermal } \\
\text { Efficiency. }\end{array}$ \\
\hline 4 & $30 \cdot 3$ & $28 \cdot 8$ \\
5 & $33 \cdot 1$ & $32 \cdot 8$ \\
6 & $35 \cdot 2$ & $35 \cdot 9$ \\
7 & $36 \cdot 8$ & $38 \cdot 3$ \\
\hline
\end{tabular}

by Ricardo, that considerable progress can be made with the use of higher compression ratios involving an annual saving in the aggregate of many million pounds sterling.

\section{Highest Useful Compression Ratio.}

H. Ricardo discovered (1918) that though detonation in the internal combustion engine is influenced by a number of important factors, for example, magneto timing and position of plugs,

TABLE II.

Highest Useful Compression Ratios of Substances (Ricardo). Substance.

Aromatic free petrol

H.U.C.R.
$4 \cdot 85$

Kerosene (heavy fuel)

Cracked spirit (53 per cent. unsaturated)

Pentane

Hexane

Heptane (normal)

Carbon disulphide

Benzene

Toluene and $\mathrm{X} y$ lene

Cyclohexane (93 per cent. pure)

Ethyl alcohol (98 per cent.)

Methyl alcohol

$4 \cdot 2$

$5 \cdot 55$

$5 \cdot 85$

$5 \cdot 1$

$3 \cdot 75$

$5 \cdot 15$ (pre-ignition

at this point)

6.9 (ditto)

$7 \cdot 0$

$5 \cdot 9$

$7 \cdot 5$

$5 \cdot 2$ (pre-ignition

at this point) $7 \cdot 3$

Butyl alcohol

$3 \cdot 9$

mixture strength, design of piston head, and cylinder shape, etc., the trouble is due to a specific failing of the fuel. Under standard conditions, using a variable compression engine, the E.35 type, he

No. 3046, Vol. 121] 
determined the point at which during increasing compression the engine gave the first audible signs of detonation. This point he has referred to as the Highest Useful Compression Ratio (H.U.C.R.), that is, the highest compression ratio which it is worth while to employ with a given fuel. If the compression ratio is raised above this limit, excessive detonation leads to pre-ignition and loss of power.

The anti-detonating action of lead-tetra-ethyl is seen at a glance from Table III., which has been

TABLE III.

\begin{tabular}{|c|c|c|c|}
\hline & & $\begin{array}{c}\text { Brake Mean } \\
\text { Effective Pressure. }\end{array}$ & $\begin{array}{l}\text { H.U.C. } \\
\text { Ratio. }\end{array}$ \\
\hline \multirow{2}{*}{\multicolumn{2}{|c|}{$\begin{array}{l}\text { Petrol } \\
\text { Petrol }+0.05 \text { per cent. lead- } \\
\text { tetra-ethyl. }\end{array}$}} & $122 \mathrm{lb} . / \mathrm{sq}$. in. & $4 \cdot 9$ \\
\hline & & & $5 \cdot 3$ \\
\hline$+0 \cdot 1$ & , & 131 & $5 \cdot 7$ \\
\hline+0.2 & ," & $138 \cdot 5$ & 6.5 \\
\hline$+0 \cdot 3$ & , & 142 & $7 \cdot 0$ \\
\hline+0.4 & ", $\quad$, & 144 & $7 \cdot 35$ \\
\hline
\end{tabular}

compiled from engine data obtained at the Air Ministry Laboratory, Imperial College of Science and Technology, and shows the effect on the H.U.C.R. of a fuel by the additions in varying amounts.

The petroleum refiner, in an endeavour to increase the yield of petrol fraction by including a part of the less volatile distillate which was formerly put into the kerosene fraction, produces a motor fuel which has a greater tendency to ' knock,' but by the use of anti-knockers this disadvantage is removed.

Condition of Engine Parts and Deposits.

The results of prolonged engine trials with fuel containing not more than 6 c.c./gal. confirm the claims made that ethyl petrol will not injure spark plugs, valves, or stems. After a 33-hour continuous run, an engine which was stripped showed a slight grey oily deposit slightly different from the usual appearance.

Typical analyses of the deposits are as follows :

\section{TABLE IV.}

I. Total weight of deposit from piston head and exhaust valve $\quad 2.3 \mathrm{gm} . / 40 \mathrm{sq} . \mathrm{cm}$.

Total weight of lead present in the petro

Deposit analysis.

Lead bromide and sulphate $\quad . \quad$. $\quad .12 \cdot 2$

Iron and aluminium bromides .. $\quad . \quad 0.2$

Carbon and volatile matter $: \quad . \quad .77 \cdot 1$

Oxides of iron and aluminium. $\quad 5.4$

Lead was found to be present in the oil, but not bromine.

TaBle V.

II. Total weight of lead added Analysis of Total weight, Iead Total weight Lead Total weight

Engine head samples :

$\begin{array}{llll}\text { Grey deposit . } \quad 38 \cdot 23 & 54.09 & 20 \cdot 7\end{array}$

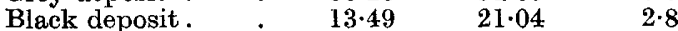

Exhaust pipe :

First $2 \mathrm{ft}$. section . $\quad 106 \cdot 14 \quad 27 \cdot 80 \quad 29 \cdot 5$

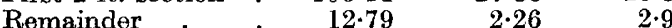

Total lead in crank case (oil and deposit)

Total lead in drop pans under exhaust outlet .

Total lead from all deposits
The amount of lead in the exhaust gases (undiluted and containing 7 per cent. carbon monoxide) was on an average $150 \mathrm{mgm}$. per $10 \mathrm{cub}$. metres.

\section{Explanations of the Phenomenon of Detonation.}

Ricardo from his engine experiments (1918) concluded that detonation differed entirely from pre-ignition, and attributed it to the spontaneous inflammation of residual unburnt charge owing to its compression by the expanding burnt and burning portion. The ignition of the residual charge under high compression and at high tem. peratures would cause a rapid rise in pressure, causing the cylinder walls to vibrate as though struck by a hammer.

Tizard and Pye extended Ricardo's line of investigation, and studied in particular the behaviour of gaseous mixtures under adiabatic compression. They found that carbon disulphide gave much greater lag periods, subsequent to the arrest of the piston before the rise in pressure due to inflammation occurred, than did ether or heptane, both of which detonate at low compressions, whilst carbon disulphide tends to raise the H.U.C.R. when added to a fuel. They concluded that detonation is a function of the temperature coefficient of the reaction velocity of combustion of a fuel, the lag period being an indication of this value.

Midgley and Boyd (1922), who first discovered the anti-detonating properties of lead-tetra-ethyl and other organo-metallic compounds, aniline, etc., in the engine, considered that detonation is set up in the cylinder when the rate of advance of the flame front reaches the velocity of sound. They attribute such a high rate of flame propagation to a high reaction velocity of combustion. The addition of substances which raise or lower this reaction velocity correspondingly should promote or delay detonation. They showed that isoamyl nitrite promotes detonation to a remarkably high extent, whilst other substances lower it to a greater or less extent, as shown by their results in Table VI.

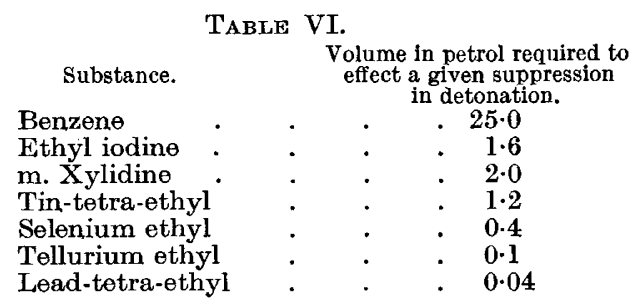

Midgley and Boyd employed a $\frac{3}{4}-\mathrm{kw}$. Delcolight engine and measured the degree of detonation by means of a rod or pin resting freely on a steel diaphragm set in the cylinder head. When detonation occurred the pin was bounced free from the cylinder, and by means of an electrolytic cell the time whilst in the air was measured from the volume of gas collected. This method is used in the United States, whilst the variable compression engine is employed in Great Britain for measuring the detonation tendency of a fuel.

The view that detonation in the engine is the

No. 3046, VoL. 121] 
same phenomenon of rapid wave propagation observed by Berthelot and Le Chatelier with gaseous explosions in long tubes is now considered to be incorrect, since the engine cylinder is too short to render this probable, and an analysis of the pressure diagrams of Tizard, Pye, and Dixon shows that there is no abrupt transition to the detonation wave during sudden compression. Egerton and Gates found that 'anti-knocks' did not affect the position of detonation in a tube $150 \mathrm{~cm}$.. long, even up to initial temperature of $230^{\circ} \mathrm{C}$. and pressures of about $100 \mathrm{lb} / \mathrm{sq}$. in.

\section{Nuclear Drop Theory of Callendar.}

A theory proposed by Prof. H. L. Callendar (1925) explains in a lucid and simple manner the phenomenon of detonation, and throws light on a large number of isolated facts left unexplained by numerous other theories. In brief, it regards detonation to be due to the simultaneous and violent ignition of a comparatively large volume of unburnt charge containing droplets or nuclei. When petrol is atomised in a current of air, the drops as they evaporate leave a residue or nucleus consisting chiefly of the less volatile constituents, such as the heavier paraffins, which have low selfigniting temperatures and serve as foci of ignition. When benzene and pentane and other fuel vapours are compressed they show cloudy condensation. Again, when gaseous mixtures, such as acetylene in air, are heated, a thick fog of ionised particles is produced which sensitises the mixture to ignition. It can be demonstrated that the self-ignition of a gaseous mixture containing liquid droplets is sometimes more than $100^{\circ} \mathrm{C}$. below that of the mixture entirely in the vapour state. The inflammation, too, is far more violent in the presence of drops. Thus, a fine spray of amyl nitrite ignited with a violent explosion when projected into a glass tube at $140^{\circ} \mathrm{C}$, , but the vapour-air mixtures caught fire relatively mildly when a temperature of $480^{\circ}$ was reached.

The subject of the formation of ionised particles or nuclei in gaseous media and the chemical changes which occur during the slow combustion in the pre-flame period during adiabatic compression is of considerable significance to the subject of detonation, and is being studied at the Air Ministry Laboratory of the Imperial College of Science and Technology. Quantitative analysis of the products of slow combustion of various fuels shows that aldehydes and acids are formed in profusion, but since these do not promote detonation in the engine, a prior compound was suspected. Further investigations indicated the presence of active oxygen, presumably in the form of organic peroxides, in the condensation products, especially when liquid drops were present and the mixture heated for a few seconds only. It was considered that the aldehydes, carbon monoxide, etc., were the decomposition products of primarily formed peroxides of the fuel, which by concentration in the nuclear drops caused self-ignition of an exceedingly violent character at relatively low temperatures. Organic peroxides are known to be violent explosives. Thus
Brodie, who first prepared alkyl peroxides, showed that a few drops detonated like a cannon. Staudinger also found that small quantities of organic peroxides adhering to the walls of a beaker were sufficient to shatter it.

\section{Engine Experiments with Organic Peroxides.}

In engine experiments carried out with the use of a synchronised sampling valve, portions of the gas mixture during the compression stroke and before ignition have been withdrawn for analysis. The oxidation products were found to contain aldehydes, acids, etc., and to be similar to those obtained during slow combustion experiments in glass tubes or bulbs in the laboratory. In a 4-stroke engine running at 1200 r.p.m.- that is, with a compression stroke of $\frac{1}{80}$ of a second duration-the presence of active oxygen was demonstrated. With the addition of iron carbonyl or lead-tetra-ethyl to the fuel, the yield of peroxides was appreciably diminished. Experiments were tried with the use of petrol to which small additions of organic peroxides and nitrogen peroxide had been added, and it was found that they all promoted detonation to a marked degree.

Moureu, Dufraisse, and Chaux, working on the autoxidation of hydrocarbons, confirm Callendar's conclusion that peroxidation occurs in the liquid state and is responsible for detonation. Callendar from his experiments (1925) showed that lead particles from the thermal decomposition of leadtetra-ethyl became concentrated on the surface of nuclear drops, which are in this manner protected against rapid oxidation and early self-ignition, the primary higher oxides formed by the oxygen molecule with the fuel being immediately decomposed by the metal and autoxidation thus delayed.

\section{Experiments with Metallic Vapours.}

Egerton and Gates demonstrated that lead vapour from a low tension arc behaved similarly to lead-tetra-ethyl in raising the self-igniting temperature of fuel mixtures and delaying detonation in the internal combustion engine. They investigated the action of anti-knockers and metallic vapours on the self-igniting temperature, determined by the Moore method, of petrol mixtures, and found, for example, that with thallium vapour a rise of $180^{\circ}$, and with lead a rise of $100^{\circ}$, was obtained. Lead-ethyl gave a rise of $90^{\circ}$, iron carbonyl $130^{\circ}$, and selenium diethyl $140^{\circ}$. They concluded that the stable peroxides of the metal react with and destroy the fuel peroxides, for example, aldehyde peroxide, and are then regenerated so that in this way the substances which autocatalyse combustion are destroyed.

\section{IONISATION AND RADIANT ENERgY.}

Detonation in the engine is accompanied by marked ionisation, and the spectrum of 'knocking' combustion shows an extension in the ultra-violet region. It was considered (Symposium on Gaseous Reactions, Faraday Society, 1926) that these phenomena are the accompaniment rather than the

No. 3046, VoL. 121] 
cause of detonation, though at one time it was considered that 'anti-knocks' acted by absorbing either the radiant energy or the electrons which by advance from the flame front increased the flame propagation and so led to detonation.

Bennett (1927), who studied the influence of substances on the ionisation of various flames and on ionisation during the slow combustion of a number of gas mixtures, found inter alia that leadtetra-ethyl, and iron carbonyl, as well as amyl nitrite, greatly increased the ionisation. It was considered, therefore, that ionisation was not a cause of detonation but merely a temperature effect.

\section{Landlocked Salmon.}

GOR many years there has existed in the middle and upper parts of the River Otra, in southern Norway, a fish known Jocally as the 'Blege,' a name applied throughout the whole of southwestern Norway chiefly to the juvenile stages of the sea trout. In fact an important fishery for the 'Blege' took place in old days in the southern parts of the Bygglandsfiord, a fishery mainly restricted to the spawning season late in the autumn and lasting until Christmas.

It is only recently ${ }^{1}$ that this fish has been discovered by Mr. Knut Dahl to be a true landlocked salmon (Salmo salar). Only exceptionally does this salmon exceed $30 \mathrm{~cm}$. (about $12 \mathrm{in}$.) in length, and for this reason $\mathrm{Mr}$. Dahl has called it a " Dwarfsalmon.' In general appearance it resembles an overgrown smolt, through the silvery coat of which the blue parr- or finger-marks are still faintly visible. An examination of such characters as the number of scales in the oblique row running backwards from the adipose fin to the lateral line, the shape and slenderness of the tail, and the short upper jaw, shows that it is indistinguishable from the young of typical migratory salmon, its only difference from the adult salmon being the retention of certain characters peculiar to the juvenile stages and its small size.

The adult fish are somewhat pelagic in their habits and roam about in schools all over the lake, unlike the ordinary trout, which appear to keep more to the shallow water and do not congregate

1 The "Blege" or Dwarf-salmon. A landlocked salmon from Lake Bygglandsfiord in Setesdal. By Knut Dahl. Skrifter utgitt av Det Norske Videnskaps-Akademi i Oslo. I. Matem.-Naturv. Klasse 1927. No. 9 . Oslo, 1927. so markedly in shoals. This roaming character is probably correlated with their feeding habits, since their food chiefly consists of the planktonic crustacean, Bosmina obtusirostris. Scale examination shows that many exhibit the typical growth periods of the migratory salmon, spending their first years in the river under poor feeding conditions, and then migrating into the lake where food is more abundant. Some, however, are born in the lake itself, and do not show this change in growth rate. A migratory habit is also exhibited by the landlocked salmon of Lake Wenern, which migrate into the river to spawn, returning afterwards to the lake, but unlike the dwarf-salmon they grow to a considerable size. Of the dwarf-salmon born under river conditions, the majority migrate after 2.5 winters. Most of the fish captured were of an age of four to six winters, and older fish were rare. Spawning took place for the first time generally in the fifth or sixth winter.

True salmon are prevented from migrating into these waters by high falls situated at Vigelandsfoss, 15 kilometres from the sea, and from geological evidence Mr. Dahl estimates that the dwarf-salmon must have arisen from fish landlocked about 9000 years ago.

At the present day the impression gained was that these fish were as numerous as the common trout, though the net fishing has diminished owing to the damming of the Bygglandsfiord as a reservoir. Mr. Dahl gives a vivid description of the sport afforded by the dwarf-salmon to the angler, and maintains that in fighting powers they surpass the trout, a supremacy which they hold also as a table delicacy.

\section{Research and Development in Australia.}

$\mathrm{T}^{\mathrm{H}}$ HE main objects of the Science and Industry Research Act (1926) of the Commonwealth Government were to reorganise the Institute of Science and Industry, which was founded in 1920, and to provide adequate funds for developing scientific and industrial research in Australia. The first Annual Report of the Council for Scientific and Industrial Research (Melbourne, 1927) contains a review of the activities of this newly constituted body between April 1926 and June 1927; the Science and Industry Research Act, 1920-26, is printed as an appendix to the Report. At the first meeting of the Council, it was decided to devote particular attention to investigations on plant and animal pests and diseases, fuel problems, preservation of foodstuffs, and forest products. In accordance with this decision, arrangements were made to secure information and reports on some of the problems concerned from Prof. T. G. B. Osborn (Adelaide), Prof. H. A. Woodruff (Melbourne), Dr. Franklin Kidd (Low Temperature Research Station, Cambridge), Mr. A. J. Gibson (Indian Forest Service), and other specialists. The various fields thus laid open to inquiry are all of first-rate importance, but a particular interest may perhaps be anticipated for Mr. Gibson's report, which is to deal with forest products problems and with the advisability of establishing a forest products laboratory in Australia.

The Annual Report affords a comprehensive summary of the many investigations in progress, some of which have already been noticed in the Council's journal (see NATuRE, Oct. 8, 1927, p. 520). Many of the activities of the Council have an intimate bearing upon the progress of agriculture in Australia. A standing committee on agriculture

No. 3046, VoL. 121] 